\title{
The Relation Between Perineal Length and Lacerations
}

\author{
During Labor
}

Fatma Ahmed Abo-Romia ${ }^{a}$

\begin{abstract}
:
Background: Perineal length is thought to affect the risk of perineal lacerations in vaginally delivered women Aim of research: to investigate the possible role of perineal length as a risk factor for development of perineal lacerations during vaginal delivery. Study design: correlation descriptive. The study was conducted at Elhelal Elahmar hospitals in Alexandria . Subjects and methods: A convenience sample of Eighty women with singleton pregnancies who went into spontaneous labor at term during the study period were included in the study. All participants were subjected to general examination, abdominal palpation and vaginal examination was performed to assess cervical effacement/length, dilatation, cervical position, consistency, membranes, liquor, presentation, position, caput, moulding and station. Perineal measurements (to the nearest $0.5 \mathrm{~cm}$ ) were taken at the beginning of the active phase of labor (effacement of $80-100 \%$ and $3-4 \mathrm{~cm}$ dilatation). The length of the perineum was determined as the distance between the fourchette and center of the anal orifice. Results: Comparison between women with perineal length $\leq 3.5 \mathrm{~cm}$ (group I) and those with perineal length $>3.5 \mathrm{~cm}$ (group II) revealed that women in GI had significantly longer $2^{\text {nd }}$ stage of labor and significantly higher frequency of perineal lacerations. Comparison between those with perineal lacerations (PL) and women without in those who didn't have episiotomy has shown that women with perineal lacerations had significantly longer $2^{\text {nd }}$ stage of labor and larger head circumferences of the newborn baby. Conclusions: Women with short perineal length are at increased risk of perineal lacerations during vaginal delivery. Other factors associated with increased prevalence of perineal lacerations are prolonged $2^{\text {nd }}$ stage of labor and increased neonatal head circumference.
\end{abstract}

Keywords: perineal length - perineal lacerations

\section{INTRODUCTION}

Perineal trauma during childbirth is very common, occurring in about $40 \%$ of women during their first birth and about $20 \%$ in subsequent births. ${ }^{(1)}$ Any laceration involving more than the perineal skin and the subcutaneous tissue must be regarded as an obstetric complication. Lacerations involving the perineal and other vulvae muscles, resulting in rectal incontinence and sexual dysfunction, have a major impact on the quality of life of the women and should be avoided whenever 
possible.(2) $^{(2)}$ evere perineal tears which the length of the perineum as a potential involve the anal sphincters and/or the risk factor. ${ }^{(6)}$ Hence, a "short" or "long" rectal mucosa are identified in $0.6-0.9 \%$ of perineum is often cited in the literature as a vaginal deliveries.(3) $^{(3)}$ risk factor for severe perineal injury without

Perineal lacerations occur during delivery of the head and shoulders of the fetus. During a normal vertex delivery it must be taken into account that the final step in the mechanism of normal birth. Therefore, it is recommended that the perineum should be supported during the process of gradual stretching, and the presenting part must be assisted in extension $^{(2)}$ Recognized risk factors for perineal lacerations include maternal factors (precipitate labor and very narrow introitus), fetal factors (large fetus, occipitoposterior position and abnormal presentation) and obstetric care factors (uncontrolled/precipitate delivery, assisted deliveries, maldirected episiotomy, extended episiotomy by tearing). ${ }^{(4,5)}$

However, very little is known about the relative interaction or confounding effect of a clear description of the normal measurements of the perineum. ${ }^{(7)}$ Episiotomy relationship to perineal length is also rarely, if ever, described in obstetric or operative texts. ${ }^{(8)}$

Aim of the study to the present study aims to investigate the possible role of perineal length as a risk factor for development of perineal lacerations during vaginal delivery

\section{Materials And Method:}

\section{Study design: correlation descriptive} design

Hypothesis was that patients with a shortened perineal body during labor are at increased risk of more extensive posterior lacerations than those with a perineal body of normal length.

\section{Materials}

This is a prospective observational study 


\section{Setting}

The study was conducted at Elhelal Elahmar hospital in Alexandria.

Subject

A convenience sample of eighty women who were available and met the criteria of the research study in the place in which of the study sample collected with singleton pregnancies who went into spontaneous labor at term during the study period were included in the study. Women with multiple pregnancies, preterm or induced labor, and those who had a cesarean delivery were excluded.

\section{Tool of data collection}

Based on review of relevant literature, questionnaire was used to interview the studied women about their age and obstetric characteristics and women with perineal lacerations .and other tool of the examination.

\section{Method}

It was tested for content validity by 5 juries, who were experts in the related field for the purpose of the study women will be approached and informed about the purpose of study before they will be asked to participate in the study and their consent will be obtained

All participants were subjected to general examination, abdominal palpation to determine the fundal level, fundal grip, pelvic grip, umbilical grip fetal lie, presentation and position. Assessment of the head engagement, expected fetal weight, monitoring of uterine contraction and auscultation of fetal heart rate were also performed. Vaginal examination was performed to assess cervical effacement/length, dilatation, cervical position, consistency, membranes, liquor, presentation, position, caput, moulding and station.

Perineal measurements (to the nearest $0.5 \mathrm{~cm}$ ) were taken in the beginning of the active phase of labor (effacement of 80 $100 \%$ and $3-4 \mathrm{~cm}$ dilatation). The length of the perineum was determined as the distance between the fourchette and center of the anal orifice. Perineal measurements 
were obtained using a non stretchable compare the basic study findings while chiflexible measuring tape disinfected by square test was used to compare betadine against the perineal tissue. ${ }^{(9)}$ As categorical data.

suggested elsewhere, ${ }^{(10)}$ we used the RESULTS perineal measurement of $3.5 \mathrm{~cm}$ as cut off

The mean age and obstetrical findings to divided the studied women into two of the studied women were shown in tablegroups: group I (G I) with perineal length $\leq$ $3.5 \mathrm{~cm}$ and group II (GII) $>3.5 \mathrm{~cm}$.

\section{Statistical analysis}

Statistical analysis was achieved using the Statistical Package for Social Science 11.0 computer program (SPSS). Numerical data were represented in the form of mean $\pm \mathrm{SD}$ while categorical data were represented in the form of number and percent. Student $t$ test was used to of $33.8 \pm 0.6 \mathrm{~cm}$. 
Table. 1 Distribution of the studded women by mean age and obstetric characteristics

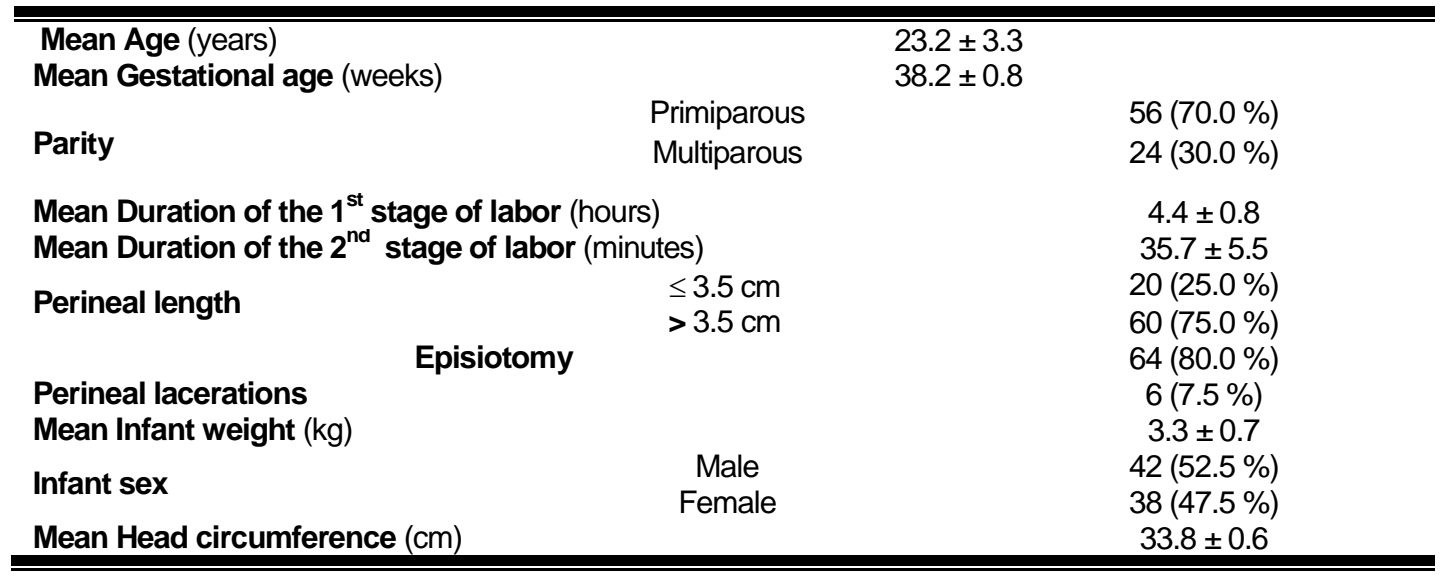

The sample size $(\mathrm{n}=80)$

Comparison between women with shown in table-2. It is clear that women in GI perineal length $\leq 3.5 \mathrm{~cm}(\mathrm{Gl})$ and those with had significantly longer $2^{\text {nd }}$ stage of labor and perineal length $>3.5 \mathrm{~cm}$ (GII) regarding the significantly higher frequency of perineal the mean age and obstetrical characteristics is lacerations.

Table-2 Comparison between women with perineal length $\leq 3.5 \mathrm{~cm}$ (GI) and women with perineal length $>3.5 \mathrm{~cm}$ (GII) regarding the mean age and obstetrical characteristics $(n=80)$

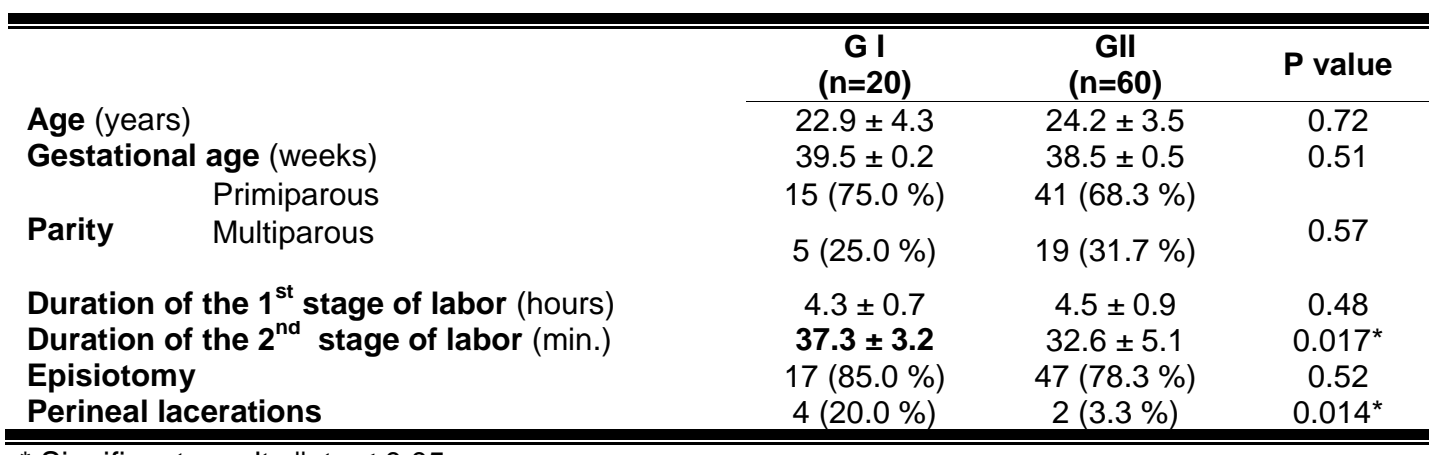

* Significant results "at $p \leq 0.05$ 
Comparison between women with illustrated in table-3. Women with perineal perineal lacerations $(\mathrm{PL})$ and those without in lacerations had significantly longer $2^{\text {nd }}$ stage of women who didn't have episiotomy regarding labor and larger head circumferences of the their age and obstetrical characteristics is newborn baby.

Table-3 Comparison between women with perineal lacerations (PL) and women without in those who didn't had episiotomy regarding the mean obstetrical characteristics $(n=16)$

\begin{tabular}{|c|c|c|c|}
\hline & $(n=6)$ & No PL $(n=10)$ & P value \\
\hline Age (years) & $24.3 \pm 2.9$ & $22.8 \pm 3.5$ & 0.28 \\
\hline Gestational age (weeks) & $39.1 \pm 0.2$ & $38.4 \pm 0.3$ & 0.25 \\
\hline Duration of the $1^{\text {st }}$ stage of labor (hours) & $4.1 \pm 0.7$ & $4.5 \pm 1.0$ & 0.19 \\
\hline Duration of the $2^{\text {na }}$ stage of labor (min.) & $39.2 \pm 1.3$ & $33.9 \pm 3.2$ & $0.011^{*}$ \\
\hline Intant Welght (kg) & $\begin{array}{l}3.4 \pm 0.6 \\
4(66.7 \%)\end{array}$ & $5(50.0 \%)$ & \\
\hline Infant sex & $2(33.3 \%)$ & $5(50.0 \%)$ & 0.52 \\
\hline Head circumference & $35.2 \pm 0.4$ & $32.9 \pm 0.9$ & $0.009^{*}$ \\
\hline
\end{tabular}

* Significant results "at $p \leq 0.05$

\section{DISCUSSION}

The diagnostic and prognostic potential of perineal length had been previously highlighted by the International Continence Society. ${ }^{(11)}$ In the present study,

The present study showed no statistically significant differences between GI and GIl patients as regards the duration of first stage of labor but the second stage of labor was significantly longer in duration in Gl than that in Gll. This coincides with the results of Rizk et al2005 ${ }^{(3)}$ who found that a short perineum prolongs the second stage of labor. On the other hand, The present result was not in accordance with that obtained by Deering et al. $2004^{(12)}$ who found no statistically significant differences between women with perineal body $\leq 3.5 \mathrm{~cm}$ and women with perineal body $>3.5 \mathrm{~cm}$ as regards the duration of second stage of labor.

The present study had also shown a significantly higher frequency of perineal lacerations in $\mathrm{Gl}$ women when compared 
with Gll women. This agrees with the results of Aytan et $\mathrm{al}^{.(13)}$ In their study there was increased risk of perineal tears in the group of women with perineal lengths $\leq$ $3 \mathrm{~cm}$. They found that the perineal length was the only maternal factor associated with lacerations in a statistically significant manner in the whole group.

Comparison between women with perineal lacerations (PL) and those without in women who didn't had episiotomy had revealed that patients with perineal lacerations had significantly longer $2^{\text {nd }}$ stage of labor and larger head circumferences of the newborn baby. This is in line with the findings of Aytan et al. ${ }^{(13)}$, who noted that fetal head circumference is associated with severe perineal lacerations. Also, Rizk et al. ${ }^{(3)}$ reported that prolonged $2^{\text {nd }}$ stage of labor was associated with increased prevalence of perineal lacerations.

So when we spot a light on the deferent between the current study and anther one, we find for what extent the midwife' should have the back ground knowledge and the detected of surrounded characteristics of labor moments.

\section{CONCLUSIONS}

From the present study the find of the following conclusion:

Women with short perineal length are at increased risk of perineal lacerations during vaginal delivery. Other factors associated with increased prevalence of perineal lacerations are prolonged $2^{\text {nd }}$ stage of labor and increased neonatal head circumference.

\section{RECOMMENDATIONS}

Based on the findings the following recommendation is suggested: precautions should be taken when delivering women with short perineal length as they are highly exposed to perineal lacerations.

\section{REFERENCES}

1. James DK, Steer PJ, Weiner CP, Gonik $B$. High risk pregnancy management Options, 3rd ed. Saunders Elsevier, Amsterdam, The Netherlands.(2005)

2. Combs CA, Robertson PA, Laros RK Jr. Risk factors for third-degree and fourth- 
degree perineal lacerations in forceps and vacuum deliveries. Am J Obstet Gynecol. (1990) ;163(1):100-4.

3. Rizk DE, Abadir MN, Thomas LB, AbuZidan F. Determinants of the length of episiotomy or spontaneous posterior perineal lacerations during vaginal birth. Int Urogynecol J Pelvic Floor Dysfunct. 2005; 16(5):395-400.

4. De Leeuw JW, Struijk PC, Vierhout ME, Wallenburg HC. Risk factors for third degree perineal ruptures during vaginal delivery. BJOG(2001);108:383-7.

5. Dahlen HG, Ryan M, Homer CSE, Cooke M. An Australian prospective cohort study of risk factors for severe perineal trauma during childbirth. Midwifery. 2007, 23:196203.

6. Christianson LM, Bovbjerg VE, McDavitt EC, Hullfish KL. Risk factors for perineal injury during delivery. Am J Obstet Gynecol 2003, 189:255-60

7. Riskin-Mashiah S, O'Brian SE, Wilkins IA Risk factors for severe perineal tear: can we do better? Am J Perinatal.2002; 19:225-34

8. Cleary-Goldman J, Robinson JN .The role of episiotomy in current obstetric practice.
Semin Perinatol.2003; 27:3-12

9. Delancey JO, Hurd WW .Size of the urogenital hiatus in the levator ani muscles in normal women and women with pelvic organ prolapse. Obstet Gynecol . 1998;91:364-368

10. Rizk DE, Thomas L: Relationship between the length of the perineum and position of the anus and vaginal delivery in primigravidae. Int Urogynecol J; 2000;11:79-83

11. Bump RC, Mattiasson A, Bo K, Brubaker LP, DeLancey JO, Klarskov $P$ et al The standardization of terminology of female pelvic organ prolapse and pelvic floor dysfunction. Am J Obstet Gynecol .1996; 175:10-17

12. Deering $\mathrm{SH}$, Carlson N, Stitely $\mathrm{M}$, Allaire $A D$, and Stain AJ: Perineal body length and lacerations at delivery. The Journal of Reproductive Medicine; 2004; 49: 306-10.

13. Aytan H, Tapisiz OL, Tuncay G, and Avsar FA: Severe perineal lacerations in nulliparous women and episiotomy type. European J. of Obstetrics \& Gynecology and Reproductive Biology; 2005; 121 : 46-5 